\title{
Article
}

\section{Interaction of Particles and Filter Fabric in Ultrafine Filtration}

\author{
Volker Bächle *(D), Patrick Morsch, Bernd Fränkle (D), Marco Gleiß and Hermann Nirschl
}

Citation: Bächle, V.; Morsch, P.; Fränkle, B.; Gleiß, M.; Nirschl, H. Interaction of Particles and Filter Fabric in Ultrafine Filtration. Eng 2021, 2, 126-140. https://doi.org/ 10.3390/eng2020009

Academic Editor: Antonio Gil Bravo

Received: 8 March 2021

Accepted: 29 March 2021

Published: 1 April 2021

Publisher's Note: MDPI stays neutral with regard to jurisdictional claims in published maps and institutional affiliations.
Karlsruhe Institute of Technology (KIT), Strasse am Forum 8, 76131 Karlsruhe, Germany; patrick.morsch@kit.edu (P.M.); bernd.fraenkle@kit.edu (B.F.); marco.gleiss@kit.edu (M.G.); hermann.nirschl@kit.edu (H.N.)

* Correspondence: volker.baechle@kit.edu; Tel.: +49-721-608-42427
Abstract: Filter fabrics are frequently used in the separation of particle-laden process streams. Especially for low-concentration and fine particles in the micrometer range, separation on filter fabrics offers considerable advantages over alternative processes. In this process, the inflowing particles are prevented from flowing through the meshes of the fabric. This interaction results in the initial resistance of the filtration not corresponding to the pure water resistance of the filter fabric. Knowledge of this increase in resistance is rare, but it leads to a significant increase in flow resistance, and thus a strong reduction in the hydraulic load on the filter apparatus. Within the scope of this investigation, measurements for 30 filter fabrics and their interaction with 3 particle systems is presented and their effect on the flow behavior is discussed. The knowledge allows an improved design of filter apparatus by correcting the pure water resistance to the resistance with particle interaction and improve the performance of ultra-fine filtration process.

Keywords: interference resistance; filter media resistance; particle-filter cloth interaction; bleeding/clogging/surface deposition; particle layer; hydraulic load

\section{Introduction}

The separation of finest particles in the one to two-digit micrometer range (and smaller) is a challenging task in mechanical process engineering. Particles which are dispersed in the gaseous medium of air have attracted public interest in recent times. This problem has become known due to the fine dust pollution in cities which is a cause for many researching areas in the experimental and computational field [1]. The separation of such fine particles from the liquid phase (e.g., water) is also challenging from a process engineering point of view. The flow of a pure liquid phase through wovens has long been part of simulations [2]. However, the filtration is determined by the interaction between filter fabric and particle system, which then has a direct effect on the performance of the filtration (particle concentration in the filtrate, throughput, etc.) [3]. If the fabric is unsuitable, there is a continuous flow of particles through the fabric and fixed limits for particle load cannot be reached [4,5]. One possibility to determine the interaction is a simulation of the process. Such simulations often require high computational effort. Therefor real filtration structures are simulated with only one particle or flat surfaces $[6,7]$. The intension of this procedure is to provide valid increasing factor of filter resistances due particle interaction.

In addition to the quality of the filtration, the size and variation of the filtrate volume flow is important. It depends strongly on the interaction between the fabric and the particles and decreases because of the built-up filter cake (at constant filtration pressure). The basis of this fact is the filtration equation based on the Darcy's law. It states that the pressure drop can be calculated from the specific cake resistance $\alpha_{H}$ multiplied by the filter cake thickness $\mathrm{H}_{\mathrm{FC}}$ and the filter media resistance $\mathrm{R}_{\mathrm{FM}}$ (Equation (1)). It also applies that the filter media resistance at the beginning of the filtration is the main resistance until the first filter cake layer has built up. Observations from some scientific studies have 
shown, however, that even the first flow of a particle-loaded suspension through the fabric influences this resistance. For this reason, this resistance is also called initial resistance $R_{\mathrm{F} .0}$ or an interference resistance $\mathrm{R}_{\mathrm{IR}}$ is introduced, which describes the increase in the filter medium resistance [8,9].

Figure 1 shows an example of the interaction of the resistances, consisting of filter cake resistance $R_{F C}$, fabric resistance $R_{F M}$ and resistance of the supporting fabric $R_{\text {Support }}$. While the cake resistance can be calculated as the product of specific cake resistance and filter cake thickness, the filter mean resistance $R_{F M}$ is determined based on expected values. In connection with this paper, research has shown that the difference in fabric resistance with pure water and with particle interaction varies by several powers of ten (Morris). This would lead to a strong misjudgment of the actual effective tissue resistance.

$$
\Delta \mathrm{p}=\left(\alpha_{\mathrm{H}} \cdot \mathrm{H}_{\mathrm{FC}}+\mathrm{R}_{\mathrm{FM}}\right) \cdot \eta_{\mathrm{f}} \cdot \dot{\mathrm{V}}_{\mathrm{F}} / \mathrm{A}
$$

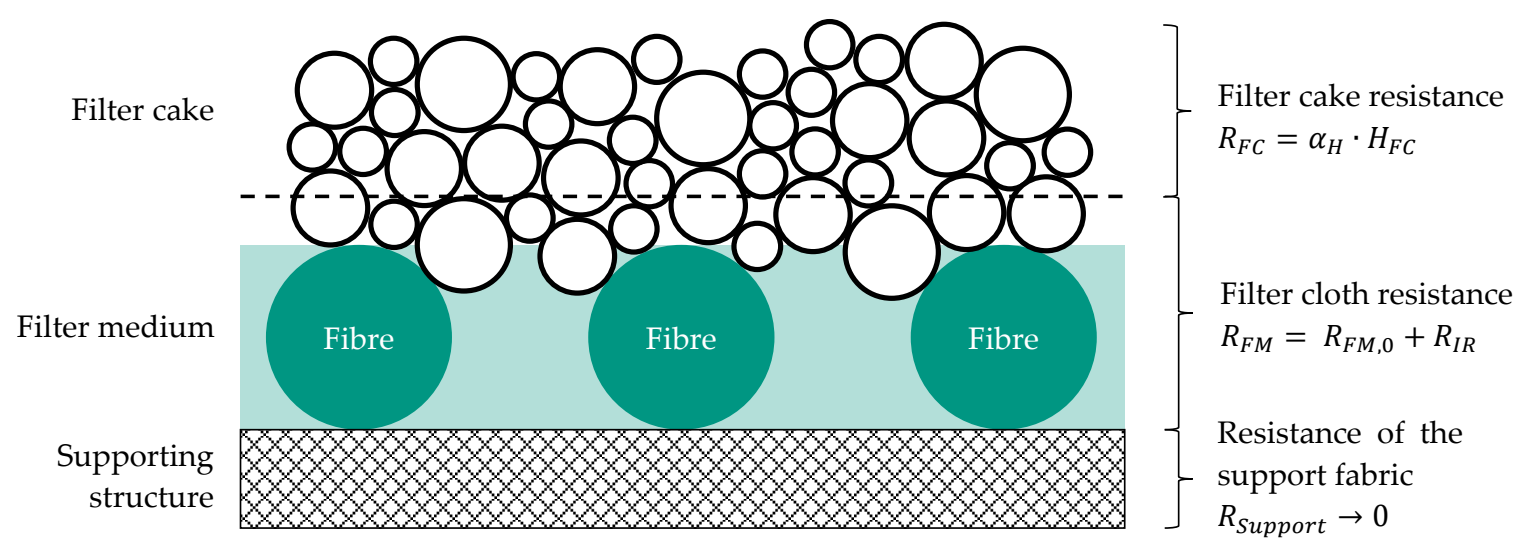

Figure 1. Schematic representation of the effective resistances in the cross-section of a filter cake $\left(\mathrm{R}_{\mathrm{FC}}\right)$, including filter ( $\left.\mathrm{R}_{\mathrm{FM}}\right)$ and support fabric $\left(\mathrm{R}_{\text {support }}\right)$.

The content of this investigation relates precisely to this interaction between fabric and particles and the increase in initial resistance caused by particle loading. Therefore, the filtration of selected plain weave $(10 ; 3$ plastic-based monofilaments, 2 plastic-based multifilament, and 5 metal-based filaments), twill weave $(15 ; 6$ plastic-based monofilament, 5 plastic-based multifilament, and 4 metal-based filaments), and satin weave (6; 6 plasticbased monofilament) with mesh sizes $\leq 25 \mu \mathrm{m}$ for 3 standard particle systems, which clearly differ in shape, is described. The aim is to broaden the understanding of the interference resistance according to the particle shape and the possibility of estimating the initial resistance for ultra-fine filtration. The results of these investigations can be applied, for example, in the filtration of other fine particle systems (filtration of tailings, etc.).

\section{Mechanisms of Filtration}

The mathematical description of filtration was first described by Darcy in the middle of the 19th century and was based on the observation of the flow through a sand filter. Darcy found a linear relationship between volume flow and the height of the fill [10]. This equation could then be further developed by assigning different resistance values to the form commonly used today, according to Equation (1). Examples are the CarmanKozeny equation and the Ergun equation for the flow through porous systems [11-13]. The investigation of Hermans and Bredée at the beginning of the 20th century also paved the way for this. In this study, the observation was written down for the first time that it is possible to differentiate between different filtration mechanisms and that these can also 
be described mathematically (see Equation (2)). This equation is based on a differential equation with two variables K and q. [14]

$$
d^{2} t / d V_{F}^{2}=K \cdot\left(d t / d V_{F}\right)^{q}
$$

Depending on which filtration process prevails, the exponent q differs. According to [14], the filtration mechanisms can be distinguished as follows:

- Cake filtration $(\mathrm{q}=0)$;

- Standard filtration (depth filtration; $\mathrm{q}=1.5$ );

- Intermediate filtration $(\mathrm{q}=1)$;

- Clogging filtration $(\mathrm{q}=2)$.

Of technical relevance for the filtration of finer particle systems is cake filtration with $q=0$, where the relationship between Equations (1) and (2) becomes clear. This is because the variable $\mathrm{K}$ is equivalent to $\left(\alpha_{\mathrm{H}} \cdot \mathrm{H}_{\mathrm{FC}}+\mathrm{R}_{\mathrm{FM}}\right) \cdot \eta_{\mathrm{f}} / \mathrm{A}$.

In addition to the integral description of the filtration process, in recent years there has also been a description of the macroscopic and microscopic separation process within and on the meshes of the filter fabric. Rushton differentiate into three possible principles of interaction between fabric and particle systems [9], which, at a constant concentration, depends largely on the ratio of the mesh and the yarn size to the particle diameter. The basis of this distinction is the observation that the resistance of the filter medium with pure water $R_{\mathrm{FM}, 0}$ is always smaller than during filtration with suspension $\mathrm{R}_{\mathrm{FM}}$. It is noted that the increase depends on the size of the particle system and is exemplarily shown in Figure $2[5,9]$.

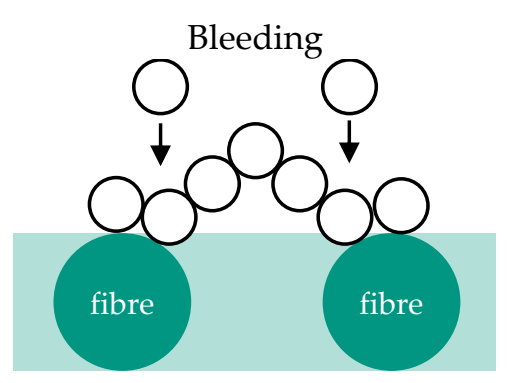

Clogging/Pore Penetration

Surface Deposition
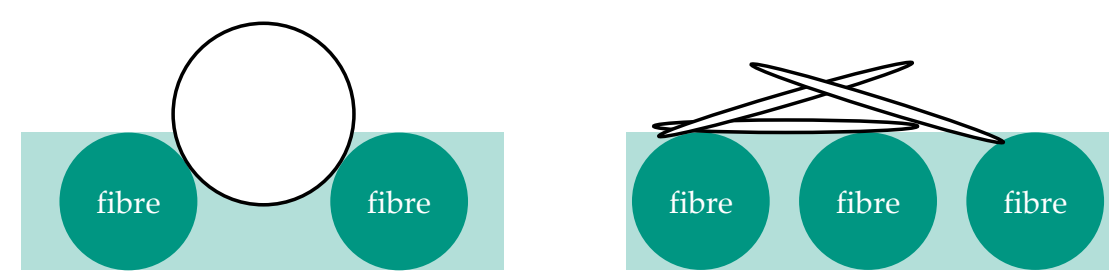

Figure 2. Schematic representation of the separation mechanisms within a fabric mesh/pore as a function of particle size and shape according to [9].

In the "Bleeding" area, in which the particle size is $\leq 65 \%$ of the mesh of the fabric, a moderate increase in the resistance value has been observed. A large turbidity surge is to be expected. The largest increase is in the "Clogging/Pore Penetration" area, where the particle size in the range $65 \%<x_{50,3} \leq 130 \%$ of the mesh of the fabric. Here, the free cross-section of the filter medium is reduced by clogging particles, which leads to an increase in the resistance value. In the "Surface Deposition" area, this increase decreases again to a stationary area. Here, the particles are $>130 \%$ of the mesh size leading to a clear interface between the fabric and the particle layer. The free cross-section of the fabric is maintained. The consideration of the "interference resistance" was firstly done by Rushton (1970). According to [9], a quantitative numerical value for the increase of the filter medium resistance $R_{F M}$ compared to the pure water value $R_{F M, 0}$ in the range of factor 5 is given. Tests have shown that especially in fine filtration, this numerical value is clearly too small. A more general differentiation is therefore provided by [8], which adheres to the usual form of resistances $\left(\mathrm{R}_{\mathrm{FC}}, \mathrm{R}_{\mathrm{FM}}\right)$ and extends this to include further resistances. He describes the increase in tissue resistance as a function of the suspension to be filtered as interference resistance $\left(\mathrm{R}_{\mathrm{IR}}\right)$. The naming by "interference resistance" was then introduced by Tichy (2007). In this work, the mesh size is reduced further, but this also does not extend to the finest filtration $<25 \mu \mathrm{m}$. Accordingly, the factor is only found up to a maximum of less than $10^{2}$. In general, however, the forming pore is seen as the cause of the flow resistance. 
In the context of this paper, both models are discussed to describe the interaction and it is attempted to transfer this to the filtration results.

\section{Method}

The basis of this investigation is the filtration by means of a pressurized filter cell as described in VDI Guideline 2762-2. The procedure is shown schematically in Figure 1. First, the process chamber is equipped with a selected filter fabric for filtration. Then the suspension is fed into the pressure chamber (Figure 3a). The filtration is carried out by means of compressed air, which presses the suspension through the fabric at constant pressure and separates it into almost particle-free filtrate and filter cake (Figure $3 b$ ). The recording of the filtrate over time allows the assignment of a specific filter cake resistance for the filter cake and a filter media resistance for the filter fabric. The evaluation of these parameters is done by the usual application of the "Time/Volume-Volume-Chart" to determine these parameters according to Equations (3) and (4). Based on the transformation and integration of Equation (1) for filtration at constant pressure, the respective parameters can then be calculated via the slope and the ordinate section.

$$
\begin{aligned}
\alpha_{\mathrm{H}} & =2 \cdot \Delta \mathrm{p} \cdot \mathrm{A}^{2} /\left(\chi \cdot \eta_{\mathrm{f}}\right) \cdot \text { Slope } \\
\mathrm{R}_{\mathrm{FM}} & =\Delta \mathrm{p} \cdot \mathrm{A} / \eta_{\mathrm{f}} \cdot \text { Ordinate Section }
\end{aligned}
$$

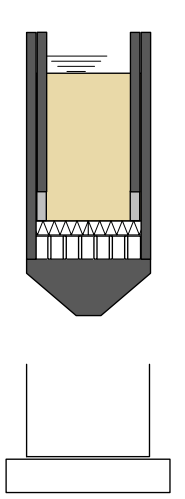

(a)

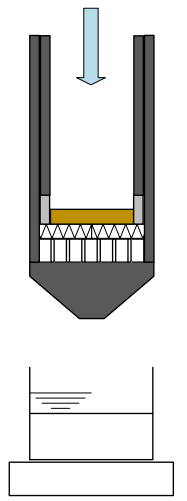

(b)

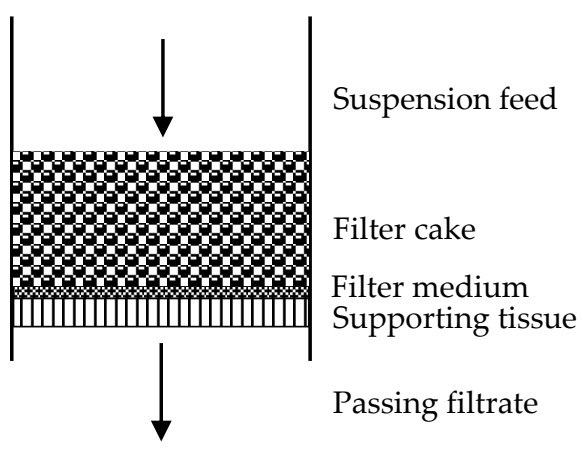

(c)

Figure 3. Schematic representation of pressure filtration by means of pressurized filter cell for the suspension feed (a), after filtration (b) and the schematic structure of the filtration process (c). The suspension is separated by a fabric into filter cake and particle-free filtrate.

For each filter media filtrations are carrying out using three standard particle systems according to [11] for characterizing the interferential resistances. The aim is to gain a deeper understanding of the increase of the flow resistance at the beginning of the filtration process by the adhesion of the particles on and into the meshes of the filter fabric. For this purpose, the respective particle systems are dispersed in regular water at a concentration of $50 \mathrm{~g} \cdot \mathrm{L}^{-1}$ and used for filtration in the pressurized filter cell. Each test requires a sample volume of $300 \mathrm{~mL}$ of this suspension. The influence of the water on the cake structure is not the focus of the investigation and is neglected at this point due to the same test preparation of the particle systems [15].

The characterization of the filter fabrics is based on manufacturer's specifications, gravimetric measurements and optical investigations using a laser scanning microscope.

\section{Materials}

The investigation is essentially based on the particle systems shown in Figure 4. These particle systems are also the subject of a study on backwashing filtration [16] and will now be used for evaluation of the interaction between cloth and particle system. This is an 
orthorhombic quartz with the designation SF300 (P1), which mineralogically consists of $98 \% \mathrm{SiO}_{2}$ (Figure $4 \mathrm{a}$ ). The modal value $\mathrm{x}_{50,3}$ is $10 \mu \mathrm{m}$ according to the manufacturer's specifications. The second particle system $\mathrm{P} 2$ is a box-shaped mixed mineral consisting of $51 \% \mathrm{SiO}_{2}$ and $45 \% \mathrm{CaO}$ as main components with the designation Tremin 283-100 and a $x_{50,3}$ value of $12 \mu \mathrm{m}$ (Figure $4 \mathrm{~b}$ ). The last particle system P3 is a needle-shaped particle system with the designation Tremin 939-304, which also consists of $\mathrm{SiO}_{2}$ and $\mathrm{CaO}$, although with the composition $49 \%$ and $47 \%$. The average needle length of an image evaluation is $\mathrm{x}_{50,1}=21 \mu \mathrm{m}$, while an average particle size $\mathrm{x}_{50,3}$ of approximately $8 \mu \mathrm{m}$ can be determined with a laser diffractometer. Here the effect of the measuring method on the determined size becomes clear. For the other two particles a measurement with a laser diffractometer results in an average particle size of $x_{50,3}=10.8 \mu \mathrm{m}(\mathrm{P} 1)$ and $\mathrm{x}_{50,3}=10.3 \mu \mathrm{m}(\mathrm{P} 2)$ [11]. For the investigation of the filter cake only the specific cake resistance as a sum parameter of porosity, shape etc. is of importance. The different size and shape of the particles should also produce a different separation behavior on and in the fabric according to [9].

(a) P1: SF300

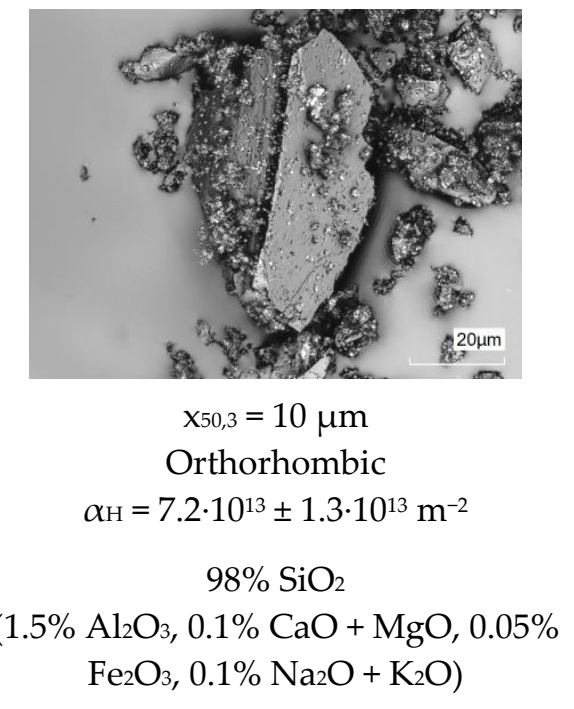

(b) P2: Tremin 283-100

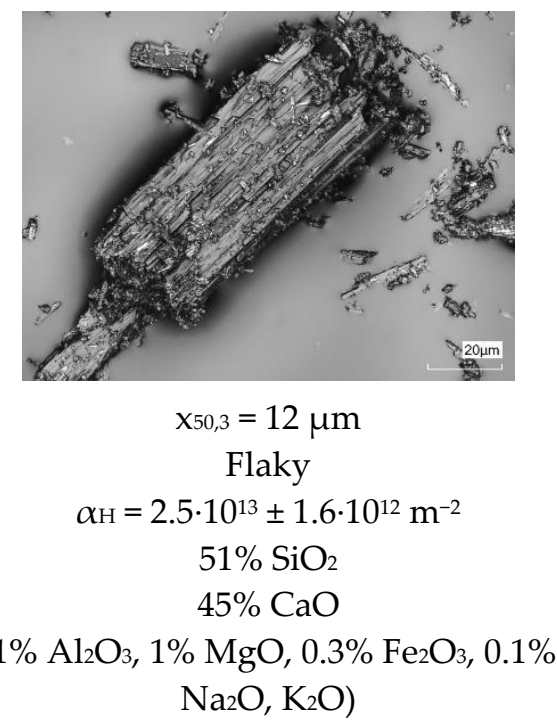

(c) P3: Tremin 939-304

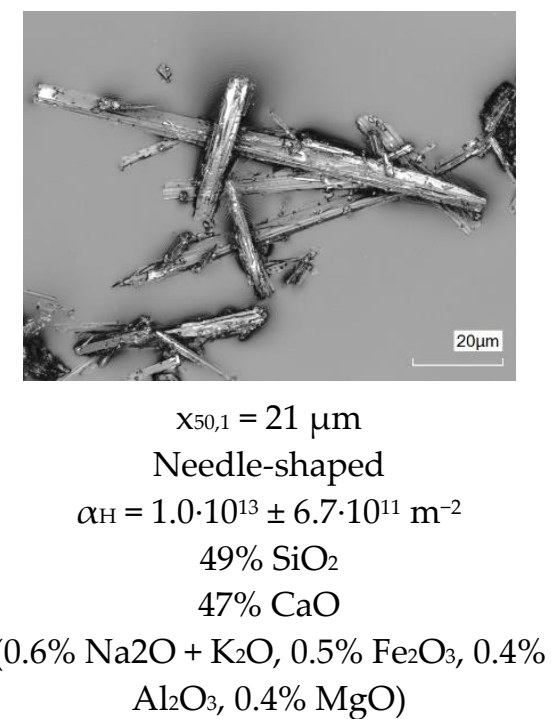

Figure 4. (a-c) Microscopic image of the investigated particle systems with orthorhombic (P1), flaky (P2) and needle-shaped (P3) particle shape.

In order to obtain the broadest possible information about the effect of particles on fabric resistance, the investigation is carried out on a large number of fabrics, which were selected on the basis of weave, material, and mesh size. The aim is to separate particles $\leq 25 \mu \mathrm{m}$, so all fabrics have a correspondingly smaller pore size. The problem is that there are many different fabrics available. These fabrics differ in repeat, fiber thickness, material, and other characteristic sizes. For this reason, the summary of the cloths is based on elaborated aspects which are classified as "important" by the authors and which are used as the basis for the assessment. The distinction of the filter fabrics is made in three groups, which are defined in more detail in the following sections:

I. Polymer-based monofilament fabrics (plain, twill, and satin weave)

II. Polymer-based multifilament fabrics (plain and twill weave)

III. Metal-based monofilament fabrics (plain and twill weave)

For the polymer-based monofilament fabrics, the characteristic features of the individual fabrics are shown Table 1. The classification of the table is based on relevant fabric data and starts with the classification into the 3 fabric groups "Plain", "Twill", and "Satin", followed by the mesh size and the material. The table is then followed by a more detailed description of the weave according to DIN ISO 9354, which includes a numerical code consisting of the fabric type (1st number), the number of warp raising and lowering 
operations (2nd and 3rd number), the number of threads that pass through this sequence (4th number), and the number of offsets until the pattern is repeated (5th number). A twill weave (20), with 4 warp lifts and one warp sink (04 01), which is passed through by one thread (01) and an offset, which in the case of the twill weave corresponds to that of the warp lifts (04), leads to the code 20-04-01-01-04 (see $5 \mu \mathrm{m}$ Twill weave in Table 1). This is followed by important values such as the number of meshes per unit area, the specific weight, the roughness according to ISO 25178 and the thickness of the fibers and the fabric based on microscopic investigations. In sum, the table presented here provides a good overview of the respective fabrics and allows an effective categorization.

Table 1. Overview of polymer-based monofilament fabrics.

\begin{tabular}{|c|c|c|c|c|c|c|c|c|c|}
\hline \multicolumn{3}{|c|}{$\begin{array}{c}\text { Fabric Type/Mesh Size in } \mu \mathrm{m} / \\
\text { Material }\end{array}$} & \multirow{2}{*}{$\begin{array}{c}\text { Weave } \\
\text { According to } \\
\text { DIN ISO } 9354\end{array}$} & \multirow{2}{*}{$\begin{array}{c}\text { Mesh per Filter } \\
\begin{array}{c}\text { Area } \\
\text { in } \mathbf{~ m m}^{-2}\end{array} \\
\\
241 \\
88 \\
64\end{array}$} & \multirow{2}{*}{$\begin{array}{c}\text { Weight per Unit } \\
\begin{array}{c}\text { Area } \\
\text { in } \mathbf{g ~ m}^{-2}\end{array} \\
\\
70 \\
120 \\
175\end{array}$} & \multirow{2}{*}{$\begin{array}{c}\begin{array}{c}\text { Surface } \\
\text { Roughness } \\
\text { (ISO 25178) } \\
\text { in } \mu \mathrm{m}\end{array} \\
\\
9 \\
90 \\
31 \\
\end{array}$} & \multirow{2}{*}{$\begin{array}{c}\begin{array}{c}\text { Thread } \\
\text { Thickness } \\
\text { Warp/Weft } \\
\text { in } \mu \mathrm{m}\end{array} \\
\\
100 / 45 \\
100 / 75 \\
126 / 176\end{array}$} & \multirow{2}{*}{$\begin{array}{c}\text { Fabric } \\
\text { Thickness (ISO } \\
\text { 5084) in } \mu \mathrm{m} \\
\\
80 \\
160 \\
185\end{array}$} & \multirow{2}{*}{$\begin{array}{c}\text { Schematic Weaving } \\
\text { Patterns, Based on [17] }\end{array}$} \\
\hline Plain & $\begin{array}{l}12 \\
14 \\
22\end{array}$ & $\begin{array}{c}\text { PET } \\
\text { PA6.6 } \\
\text { PET }\end{array}$ & & & & & & & \\
\hline Twill & $\begin{array}{l}5 \\
11 \\
14 \\
15 \\
20 \\
25 \\
\end{array}$ & $\begin{array}{l}\text { PP } \\
\text { PET } \\
\text { PP } \\
\text { PET } \\
\text { PET } \\
\text { PP } \\
\end{array}$ & $\begin{array}{l}20-0401-01-04 \\
20-03 \quad 01-01-03 \\
20-0201-01-02 \\
20-03 \quad 01-01-02 \\
20-03 \quad 01-01-03 \\
20-02 \quad 01-01-02 \\
\end{array}$ & $\begin{array}{c}5 \\
29 \\
40 \\
26 \\
35 \\
11 \\
\end{array}$ & $\begin{array}{l}295 \\
240 \\
136 \\
235 \\
235 \\
210 \\
\end{array}$ & $\begin{array}{c}3 \\
29 \\
40 \\
8 \\
30 \\
24 \\
\end{array}$ & $\begin{array}{c}212 / 822 \\
132 / 429 \\
168 / 161 \\
175 / 283 \\
128 / 160 \\
61 / 187 \\
\end{array}$ & $\begin{array}{l}420 \\
265 \\
200 \\
265 \\
260 \\
320 \\
\end{array}$ & 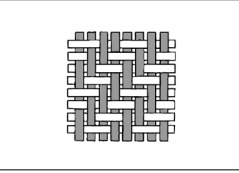 \\
\hline Satin & $\begin{array}{c}6 \\
11 \\
18 \\
18 \\
22\end{array}$ & $\begin{array}{l}\text { PP } \\
\text { PP } \\
\text { PP } \\
\text { PP } \\
\text { PET }\end{array}$ & $\begin{array}{l}20-02 \\
30-04-02-01-01-02 \\
20-0802-02-04 \\
30-0402-02-02 \\
30-0602-01-03\end{array}$ & $\begin{array}{l}6 \\
5 \\
3 \\
4 \\
5\end{array}$ & $\begin{array}{l}435 \\
330 \\
370 \\
447 \\
395\end{array}$ & $\begin{array}{c}11 \\
13 \\
13 \\
7 \\
11\end{array}$ & $\begin{array}{l}164 / 898 \\
371 / 572 \\
269 / 294 \\
227 / 443 \\
235 / 604\end{array}$ & $\begin{array}{l}590 \\
400 \\
500 \\
714 \\
380 \\
\end{array}$ & 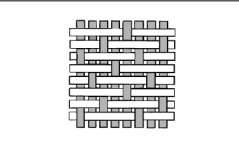 \\
\hline
\end{tabular}

It is noticeable here that the fabric thickness does not correspond to the sum of warp and weft thread. This is due to a calendering of all fabrics, which reduces the fabric thickness and thus the pore size. Pore sizes smaller than $20 \mu \mathrm{m}$ are not possible using monofilament fibers without calendering. The difference between twill and satin fabrics is mainly the offset of the adjacent warp yarn. A distinction is not always easy to make. This becomes clear with the satin fabric with $6 \mu \mathrm{m}$ and $18 \mu \mathrm{m}$ pore size, which can also be assigned to the group of twill fabrics according to DIN 9354.

To cover fabric types of different fiber types, the fabrics under investigation have been extended by the group of "polymer-based fabrics, woven from multifilament yarns". These also have a pore size $\leq 25 \mu \mathrm{m}$ and are represented with a plain and twill weave. A multi-filament fiber consists of many individual fibrils, and therefore has a large surface in which particles can adhere. According to [5], part of the flow passes through the fiber itself, whereby particles are also deposited within the fiber and thus reduce the longevity of the fabric. In contrast, the residual contamination of the filtrate is theoretically lower. Table 2 shows the characteristic features of the fabrics used. The large thread diameters measured with a laser scanning microscope are striking. With multifilament fibers, the individual fibrils of the fibers can move towards each other, which causes the thread to be compressed during weaving due to the tension. The thread is therefore not round but having an oval shape. This can occur in different orders of magnitude and explains why the thickness of some fabrics is smaller than the measured thread diameter. The mechanical properties of the fabric depend largely on the material and weave. The same also applies to the filtration performance, because of the number of meshes per unit area. Due to the fibrils, the stability of these fabrics can be rated as very good compared to other types of fibers. 
Table 2. Overview of polymer-based multifilament fabrics.

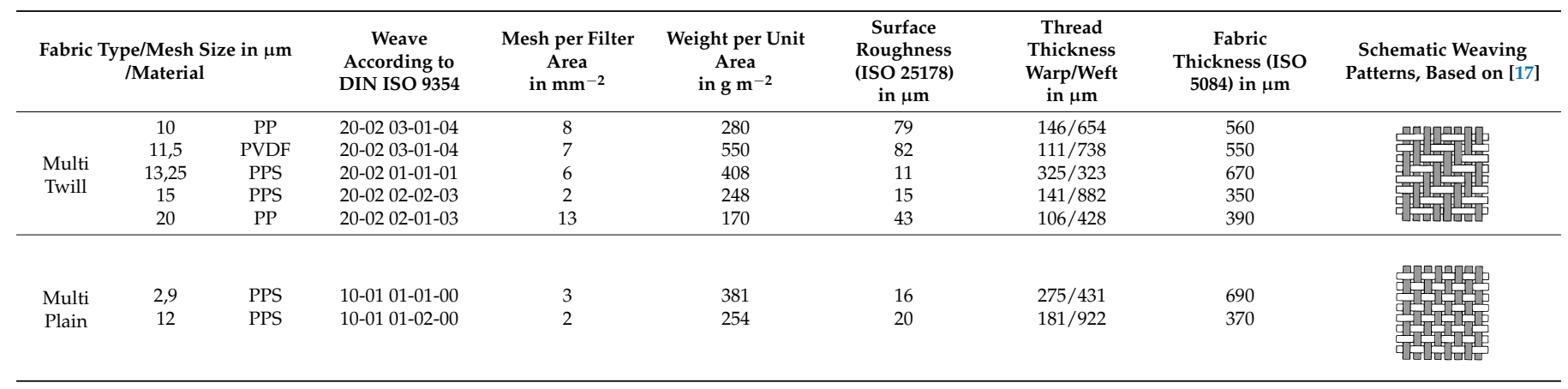

The last group of the investigated fabrics includes metal-based plain and twill weaves with monofilament fibers and a pore size of again $\leq 25 \mu \mathrm{m}$. These are summarized in Table 3. Metals as a material have a higher temperature resistance, which makes them suitable for use at high temperatures, such as in the exhaust air purification of a combustion process. Metallic filter fabrics also have the advantage that considerably finer threads can be woven according to their mechanical properties. This enables finest mesh sizes up to $6 \mu \mathrm{m}$ without calendering. Due to the finer threads used metal cloths have a larger free filter surface for the same mesh size compared to plastic-based media. This can be seen from the high number of meshes per unit area in Table 3, which is two powers of ten higher than for woven plastic fabrics with the same pore diameter. In addition, the use of thinner yarns results in lower surface roughness. The improved filtration performance is therefore offset by a correspondingly higher price, which is why the use of metal filter cloths is also an economic decision. In addition to a higher price, metal filter fabrics are usually more susceptible to oxidation, which is why they are avoided in chemical applications.

Table 3. Overview of metal-based multifilament fabrics.

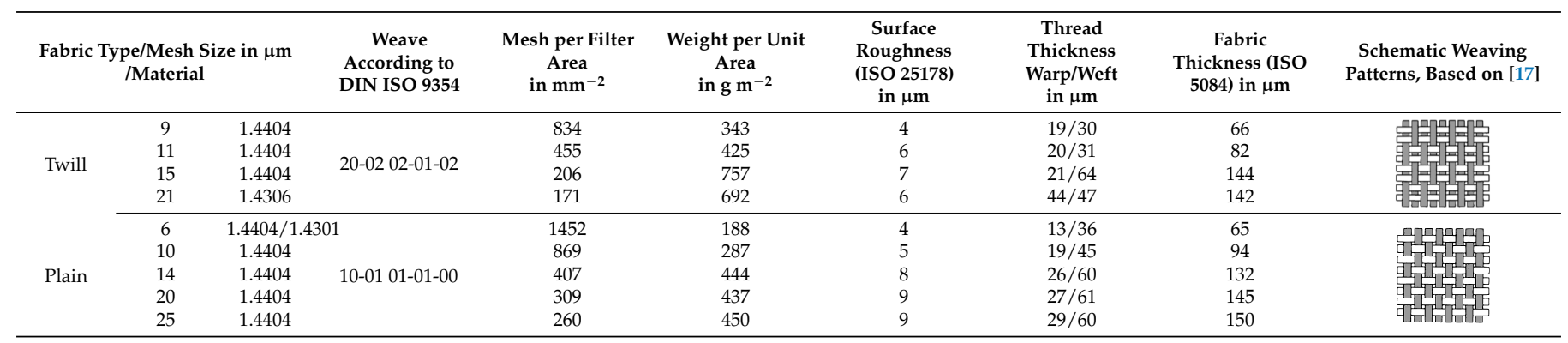

\section{Interpretation}

Due to the large number of measurements on a variety of tissues, the evaluation is carried out within the three tissue categories from the chapter "Materials". Based on this, a cross-group evaluation is carried out to change the filtration properties by adding particles. In the following chapter "Conclusion" these findings are summarized, and practice-relevant recommendations are made.

\subsection{Polymer-Based Monofilament Fabrics}

As already listed in Table 1, the group of plastic-based monofilament fabrics is represented by different weave types and mesh sizes. As described in the chapter Methodology, all fabrics are filtered with the particle systems presented in Figure 2. The filter medium resistances of this interaction of particles with the filter fabric are shown in Figure 5. Further included there are the specially determined filter medium resistances with pure water. Regarding the measured pure water resistances, a decrease of the resistance value can be observed with increasing pore size. When filtering the fine particle system P1 with a specific 
cake resistance of $7 \cdot 2 \cdot 10^{13} \mathrm{~m}^{-2}$, at $\mathrm{x}_{50,3}=12 \mu \mathrm{m}$ particle size, the $12 \mu \mathrm{m}$ fabric achieves an initial resistance of approximately $4 \cdot 10^{10} \mathrm{~m}^{-1}$, while the 14 and $22 \mu \mathrm{m}$ fabrics have $\sim 1 \cdot 10^{10} \mathrm{~m}^{-1}$. Here, no further decrease of the resistance value is observed with increasing mesh size from 14 to $22 \mu \mathrm{m}$. By including the theory according to [4] of different deposition processes in and on the fabric, this was not to be expected, since the fine particles of P1 should clearly penetrate the meshes and flow through the $22 \mu \mathrm{m}$ fabric. Noteworthy also is the increase in resistance to the particle-free resistance by water. Regarding potency, an increase by a factor of $10^{2}$ can be observed. This is significantly greater than factor 5, which was published after [4]. For finer tissues it can therefore be assumed that the expression of the interference resistance increases considerably. This statement must be verified by the other tissues and particle systems. In the case of the platelet-shaped particle system P2, the tendency expected from P1 can also be seen. Compared to the pure water resistance, an increase by a factor of $10^{2}-10^{3}$ is also valid. In the case of the needle-shaped P3, no significant difference can be observed in all three tissues. Only the minimum at $14 \mu \mathrm{m}$ is noteworthy, but this can be explained by the standard deviation of the same order of magnitude. All three particle systems are in the middle to upper range of $10^{9} \mathrm{~m}^{-1}$. Here, a "surface deposition" is present, which has a clear interface between tissue and particle systems because of the significantly larger particles compared to the meshes of the tissue. Accordingly, the increase in the filter medium resistance is due to "covering" free meshes (sphere-hole model according to [5]) and is in the order of $10^{2}$. In total, the filter medium resistance has increased by a factor of $10^{2}-10^{3}$ due to the interaction of particles to mesh. Orthorhombic particles exhibit less spherical obstruction when flowing through the mesh than, for example, needle-shaped particles. As a rule, a particle which has significantly larger deviations from the ideal sphericity (a sphere has a sphericity of one) has an increasing spherical obstruction compared to the meshes of tissues. When penetrating into the pore, a narrowing occurs, which reduces the hydraulic cross-section and leads to an increase in resistance in terms of process technology.

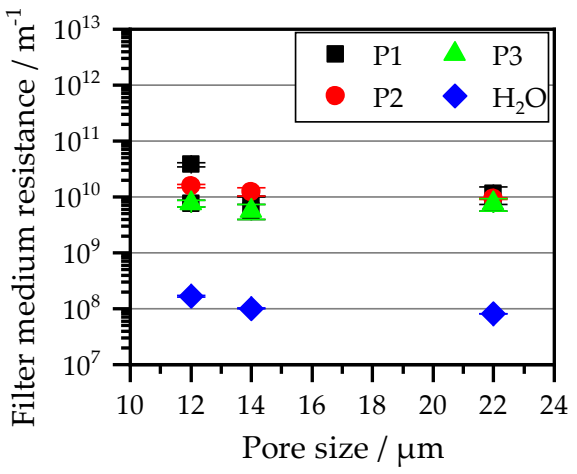

(a) Plain

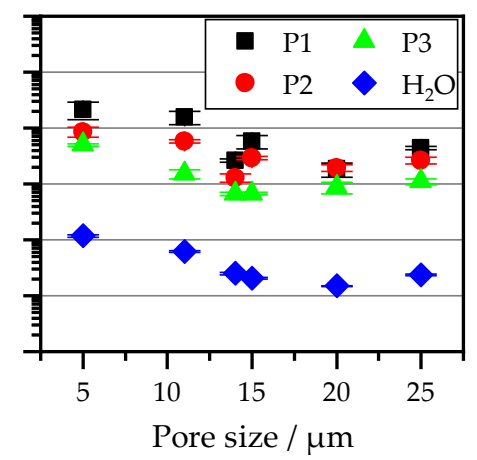

(b) Twill

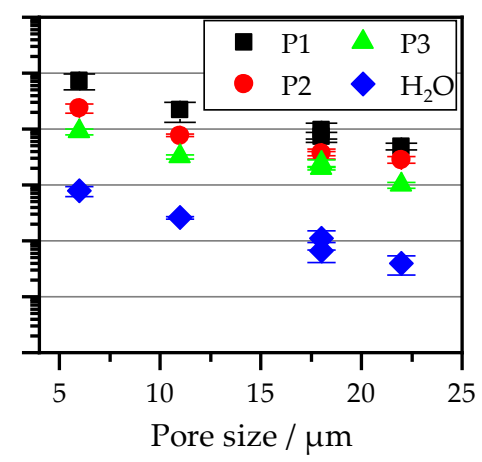

(c) Satin

Figure 5. Overview of the tissue resistances for plain (a), twill (b) and satin fabrics (c) in $\mathrm{m}^{-1}$ of the plastic-based monofilament tissues (Table 1) with interaction of the particles from Figure 2.

In addition to the plain fabrics, the twill fabrics are represented by six fabrics with mesh sizes from 5 to $25 \mu \mathrm{m}$. Analogous to the plain weave, a decrease in the filter medium resistance with the particle systems can be observed in the twill weave, starting with the orthorhombic P1, via the plate-shaped P2 to the needle-shaped P3. Only the $20 \mu \mathrm{m}$ fabric has an exception in that the filter medium resistances of both particle systems P1 and P2 are similar. Regarding the relationship between mesh size and particle diameter, the area of "bleeding" and "clogging" must be assumed here. An explanation for this behavior is therefore pure conjecture, since a comparison with fabrics of similar behavior is not possible in this study. Another special feature of the twill fabrics is the course of the filter medium resistance of 5 to $25 \mu \mathrm{m}$ within the filtration with P1. Here, a steady decrease of the resistance value can be observed. Only the $20 \mu \mathrm{m}$ fabric has a local minimum 
of $1.9 \cdot 10^{10} \mathrm{~m}^{-1}$. In initial attempts to interpret this behavior, an interaction of the large number of meshes in combination with the larger mesh size (bleeding and clogging) must therefore be mentioned as a possible cause. Here, the flow velocity within the meshes is lower, which makes it easier to deposit particles and reduce the mesh size. A measurement of the pore size distribution using porometry confirms this assumption. Regarding the two other particle systems P2 and P3, a deviation from the expected behavior can also be assumed. For P2 and P3, the largest resistance value within this group can be observed for the $5 \mu \mathrm{m}$ mesh. As expected, this decreases at $11 \mu \mathrm{m}$. For the following fabrics with 14 to $25 \mu \mathrm{m}$, however, a quasi-stationary resistance value of $\sim 2 \cdot 10^{10} \mathrm{~m}^{-1}$ for P2 and $\sim 8.2 \cdot 10^{9}$ for P3 can be observed. The smallest values are achieved by the fabrics with the largest number of meshes within this group. The assumption of the interaction between mesh size and mesh number is confirmed here. By extending the observation to surface roughness, it can be observed that the fabrics with lower roughness down to below $30 \mu \mathrm{m}$ show the greatest increase in filter medium resistance, while fabrics with $\geq 30 \mu \mathrm{m}$ show the smallest increase. Particularly with resistance values in the order of $10^{9} \mathrm{~m}^{-1}$, a larger measurement variation can be observed here, which can falsify the sequence. The surface roughness can therefore only be evaluated in connection with the number of meshes. Statements based on surface roughness alone are not possible. In total, the filter medium resistance has increased by a factor of $10^{2}-10^{3}$ for four of five filter cloths due to the interaction of particles to fabric. The $11 \mu \mathrm{m}$ filter cloth shows an increase of $10^{1}$ when interacting with P3. Otherwise, an increase of $10^{2}$ can also be seen here with interaction with P1 and P2. What becomes clear is that the increase in resistance is independent of the mesh size.

The group of plastic-based satin fabrics is represented by five fabrics with mesh sizes from 6 to $22 \mu \mathrm{m}$. With a focus on the weave, satin fabrics are like twill fabrics, except for the larger offset number and the large number for warp lifting, which is evident from the high pure water resistance. This is the highest of all the $6 \mu \mathrm{m}$ fabrics with $7.8 \cdot 10^{9} \mathrm{~m}^{-1}$ and even for the $22 \mu \mathrm{m}$ satin fabric in the $3.9 \cdot 10^{8} \mathrm{~m}^{-1}$ range it is still very high compared to the twill fabrics. A special feature of this group of fabrics is that two fabrics have the same mesh size $(18 \mu \mathrm{m})$. While one fabric has a filter mean resistance of $6.7 \cdot 10^{8} \mathrm{~m}^{-1}$, the other fabric has a value of $3.6 \cdot 10^{8} \mathrm{~m}^{-1}$. This also corresponds to the meshes per unit area, in the first case three meshes per $\mathrm{mm}^{2}$, while the other, with four meshes per $\mathrm{mm}^{2}$, has an assumable larger free filter area, and accordingly has a lower resistance. In these fabrics, the fabric with the larger specific number of meshes per unit area is also slightly rougher $(13 \mu \mathrm{m})$ than the other fabric $(7 \mu \mathrm{m})$.

When evaluating the influence of particle interaction, it is noticeable that for all three particle systems the trend "Decreasing resistance value with increasing mesh size" is given in the case of satin fabrics, considering the standard deviation. The increase corresponds to $10^{1}-10^{2}$ and leads to the conclusion that for fabrics with a high resistance value, in the case of the pure water value, a smaller increase in the resistance value with particle interaction can be expected. The absolute value of satin fabrics, for example, is in the same order of magnitude of potency as that of twill fabrics like the weave, although the prefix differs slightly. Regarding Table 1, an $18 \mu \mathrm{m}$ fabric should also be mentioned which, contrary to the manufacturer, is to be classified as twill fabric according to DIN ISO 9354. A clear distinction between satin and twill fabrics is questioned here, not only in terms of weaving technology but also in terms of process technology.

The increase in flow resistance shown in the previous illustrations results from the separation mechanism within the hydraulic diameters of the tissues. This can be seen by the microscope image in Figure 6. While the orthorhombic particle system can penetrate deeply into the three-dimensional structure of the fabric due to its scaliness and block the meshes there, this characteristic is less pronounced with the flaky particle system. With increasing particle size and/or deviation from the ideal sphericity, as is the case with the needle-shaped particle system, the deposition within the fabric and in the meshes becomes more appropriate and the increase in flow resistance is smaller. 


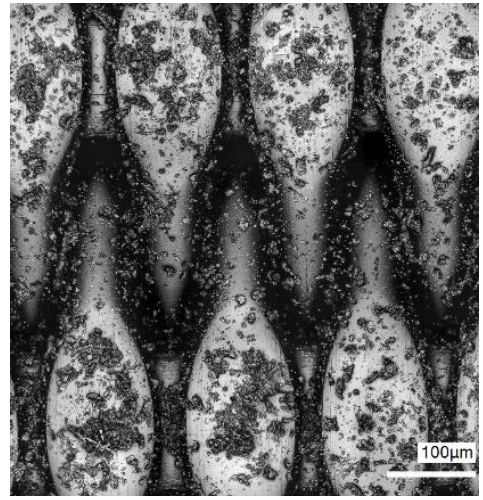

(a) Orthorhombic (P1)

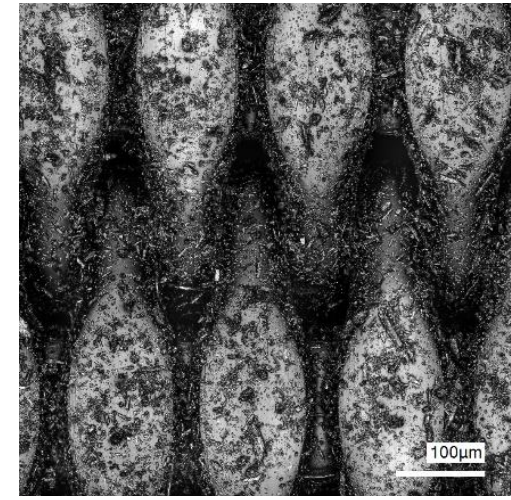

(b) Flaky (P2)

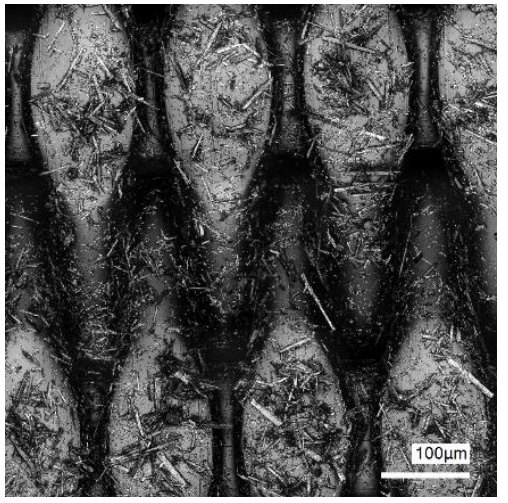

(c) Needle-shaped (P3)

Figure 6. (a-c) Separation of the different particle systems (P1-P3) for the $22 \mu \mathrm{m}$ monofilament fabric (plain wave).

\subsection{Polymer-Based Multifilament Fabrics}

The second group of plastic-based filter fabrics are the multifilament fabrics, which are divided into twill and linen fabrics. The summary of the fabrics is shown in Figure 7. In contrast to the monofilament fabrics, this group of fabrics allows particles to flow through, and thus be deposited in, the multifilament fibers [4]. The characteristic of this flow through the fibers is also based on the treatment of the fibers (twisting, calendering, etc.). A look at the water resistance of these fabrics shows that with decreasing mesh size the pure water resistance with twill weave shows almost no change. Only the two plain fabrics show a higher resistance value, which is greater by a factor of 10 for the $2.9 \mu \mathrm{m}$ mesh width than for the twill weave. One explanation for the constant resistance value is the increasing flow through the fibers, instead of the very fine meshes, with finer weaving. Regarding the resulting filter medium resistances due to interaction with the particle system, the trend is not met by monofilament fabrics. A larger mesh is not the same as a smaller filter medium resistance. Like pure water, all three particle systems have hardly any change in the filter medium resistance over the mesh size variation. Again, the two plain fabrics with the highest values in the filter mean resistance are conspicuous. This is where the influence of particle interaction is most obvious. The twill woven fabrics with a mesh width of $13.25 \mu \mathrm{m}$ have the highest filter mean resistance within the multifilament fabrics and this is of the same order of magnitude as that of the $12 \mu \mathrm{m}$ plain fabric. This also applies to the other particle systems in both fabrics. In this case, a correlation between the mesh size and the filter medium resistance can be observed, depending on the type of weave. While the plain of monofilaments has the lowest resistance within the plastic-based fabrics, multifilaments, and plain fabrics tend to have a higher filter medium resistance. This is also because, based on a bubble-point investigation, the fabrics have finer meshes due to the manufacturing process. The interaction with particles, however, causes the resistance of plain fabrics to increase more strongly than that of twill fabrics. A higher filter resistance for plain weaves is also calculated by Tung et al. which proofs similar trends between CFD simulations and our experiments [18].

In general, it can be stated that the filter medium resistance has increased by a factor of $10^{1}-10^{2}$ due to the interaction of particles with fabric [19]. The multifilament fabrics also show a lower dependence of the measured mesh size and the filter medium resistance. The different separation mechanisms in the meshes (P3), on the multifilament fibers (P2) and both (P1) are shown for the three particle systems in Figure 3 for the $20 \mu \mathrm{m}$ twill fabric. 


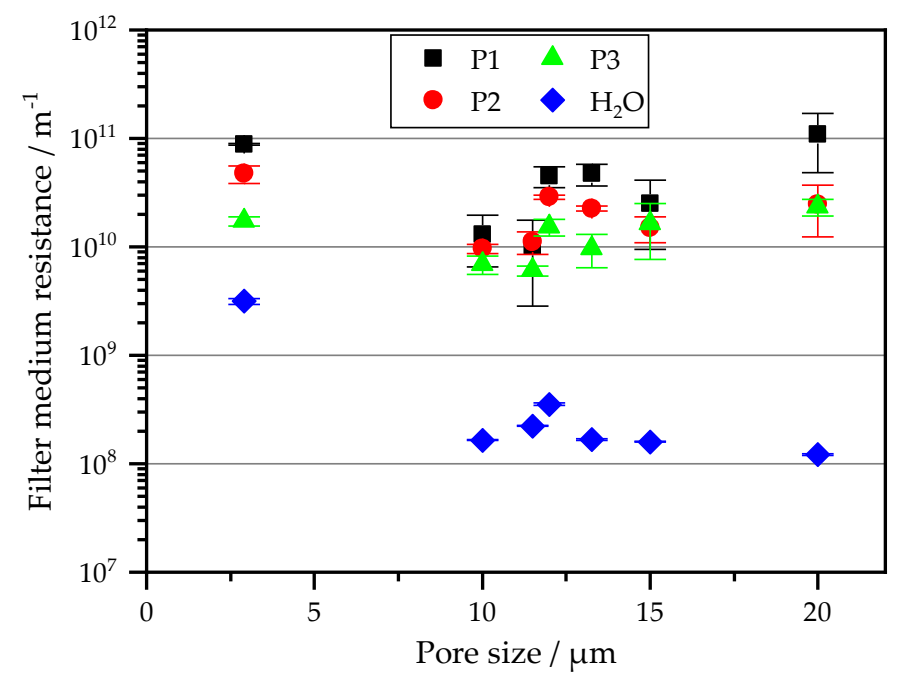

Figure 7. Overview of the fabric resistances in $\mathrm{m}^{-1}$ of the plastic-based multifilament fabrics (Table 2) with interaction of the particles from Figure 2.

\subsection{Metall-Based Monofilament Fabrics}

The last group of tissues includes metal-based tissues. Like the multifilament fabrics, these are divided into twill and plain fabrics. The twill fabrics are represented by four variations from 9 to $21 \mu \mathrm{m}$, while the plain fabrics are represented by five variations from 6 to $25 \mu \mathrm{m}$ (see Figures 8 and 9). A special feature of this group of fabrics is the finer weaving of metal-based filter fabrics without the need for pore reduction by calendering. This is illustrated by the fabric thickness, which almost corresponds to the addition of the weft thread with double warp thread (see Table 3 Measurement inaccuracy causes existing deviations). The fibers can thus be judged as "almost round" and no flattening was caused by calendering. Regarding the water resistance of the 9 to $21 \mu \mathrm{m}$ twill fabrics, a steady decrease of the resistance value can be observed, whereby the difference between the $9 \mu \mathrm{m}$ and $11 \mu \mathrm{m}$ fabric is only slight. This behavior is in line with expectations, since the pressure drop decreases due to the larger meshes, with a simultaneous moderate increase in fiber diameters (see Table 3). In the case of plain fabrics, the course of the water resistance decreases with increasing mesh size, analogous to the other fabrics used.

If we now look at the particle interaction in the metal-based fabrics, deviations from the expected behavior are noticeable. In the case of P1, the observed trend is broken by the polymer-based monofilament fabrics. In Figures 5 and 7 it can always be observed that with increasing mesh size, despite interaction with particles, the filter medium resistance decreased. This no longer applies to the metal-based monofilament fabrics with the "twill" and "plain" weave. Here, the resistance value is constant or tends to increase slightly with increasing mesh size. It must be assumed that the particles of P1 are deposited in the pores of the fabric and this leads to the highest measured filter mean resistance of the group of metal-based fabrics. Regarding the other particle systems P2 and P3, a tendency towards increasing filter mean resistance can also be observed. However, by taking the standard deviation into account, no significant difference can be said to exist between the twill and plain fabrics and the fabrics with different mesh sizes. The filter mean resistance of the plain fabrics is like that of the twill fabrics. Metal woven wire cloth tends to have a lower resistance value for similar mesh sizes than the plastic-based woven fabrics. Calendering is a possible cause of the differences to the polymer-based fabrics, which has a direct influence on the pore size and geometry. 


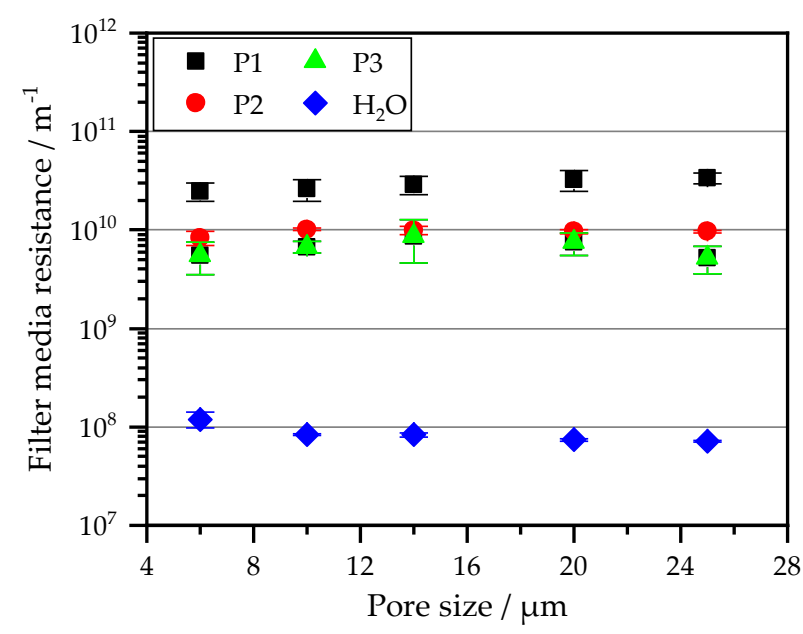

(a) Plain

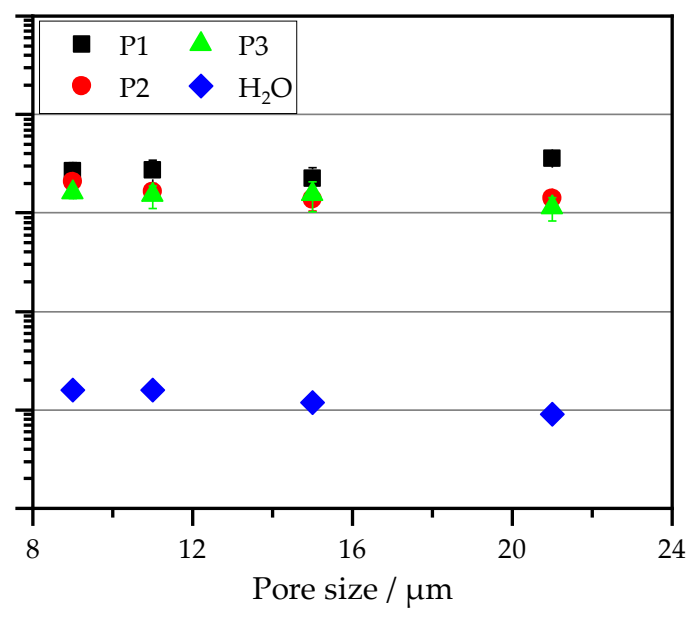

(b) Twill

Figure 8. Overview of the fabric resistances in $\mathrm{m}^{-1}$ of monofilament metal-based plain (a) and twill (b) fabrics (Table 3) with interaction of the particles from Figure 2.

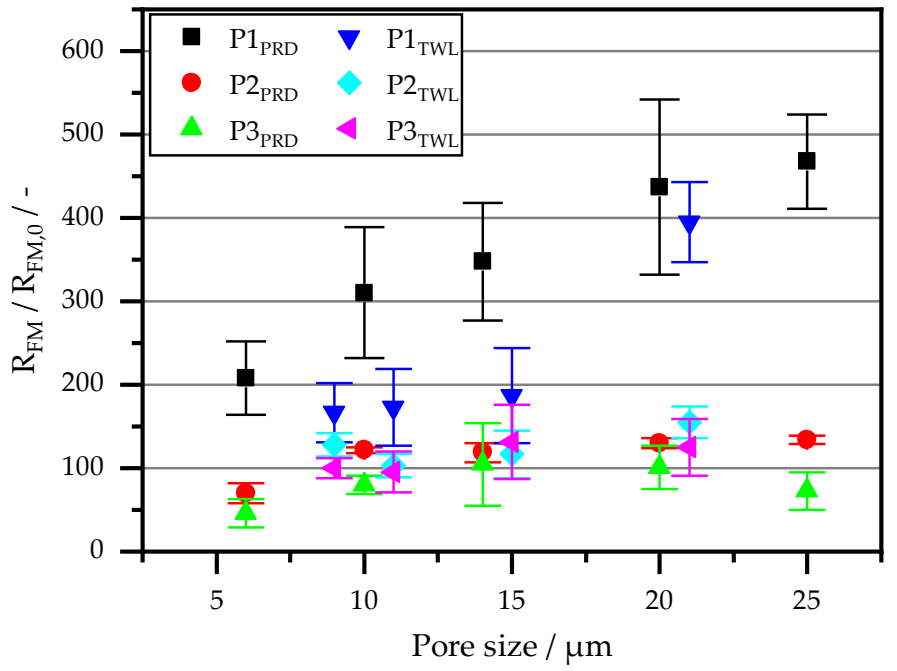

Figure 9. Relative change of the filter medium resistance with particle interaction $R_{F M}$, related to the clear water resistance $\mathrm{R}_{\mathrm{FM}, 0}$, over the mesh size of metal-based plain weave and twill weave.

A transfer into the form according to [3] is not appropriate, since the diagram does not show a concentration dependence, which according to [20] is a parameter not to be neglected. The concentration of the tests was based on [11].

\section{Conclusions}

Within the scope of this investigation 30 filter fabrics of different materials, fiber types, and fabric types were examined for their filter medium resistance with particle interaction. All fabrics have mesh sizes $\leq 25 \mu \mathrm{m}$ and are therefore suitable for ultra-fine filtration. For the characterization, the fabrics have been divided into three groups. The subdivision is based on the weave (plain, twill, satin), the fibers used (monofilament, and multifilament), as well as the material category used (polymer, and metal). The tests were carried out based on regular pressurized filter cell tests according to VDI guideline 2762-2 with focus on the filter medium resistance. The aim was to investigate the order of magnitude of the filter medium resistance through interaction with an orthorhombic (P1), a flaky (P2) and a needle-shaped (P3) particle system. This is based on publications according to [5,19], which have already dealt with similar topics in another mesh size range. 
The result of this study is that the filter mean resistance for fabrics $\leq 25 \mu \mathrm{m}$ is independent of the mesh size, increases by a factor of $10^{1}-10^{2}$. This increase is independent of the weave and could be observed for plain weave as well as twill and satin fabrics. The former showed a tendency towards $10^{1}$, whereas fabrics tend to increase by a factor of $10^{2}$ with increasing warp lift and offset number. The course according to [5] is not appropriate, since the diagram does not show a concentration dependence, which is an important parameter for the formation of solid bridges on the pores after [12]. If the increase in the filter medium resistance due to particle interaction is now transferred to the reduction of the hydraulic load $\dot{V}_{\mathrm{f}} / \mathrm{A}=\Delta \mathrm{p} \cdot \eta_{\mathrm{f}}{ }^{-1} \cdot \mathrm{R}_{\mathrm{tot}}{ }^{-1}$ of the filter medium, a reduction in the hydraulic load of 90-99\% (Based on $R_{\text {tot }}=10^{8} \mathrm{~m}^{-1}$ as reference) is shown. This can be seen from the Darcy equation, where the hydraulic load decreases because of the increase in filter medium resistance and thus an increase in pressure drop through the filter. This example shows that the choice of filter medium at $10^{9} \mathrm{~m}^{-1}\left(0.1 \mathrm{~m}^{3} \cdot \mathrm{m}^{-2} \cdot \mathrm{s}^{-1}\right.$; for example $\left(\Delta \mathrm{p}=10^{5} \mathrm{~Pa}\right.$ : $\eta_{\mathrm{f}}=10^{-3}$ ), Pas the $6 \mu \mathrm{m}$ metal-based plain fabric, instead of the $6 \mu \mathrm{m}$ polymer-based satin fabric) can significantly improve the hydraulic load. Effects on subsequent regeneration steps also depend on fabric type and mesh size [21,22].

An additional conclusion is that the increase of the filter medium resistance shows a structure dependence of the particles. Thus, orthorhombic particles (P1) generate the greatest resistance in all tissues. This is due to the interaction of the particles which, due to their structure, can penetrate deep into the tissue and only slightly obstruct each other spatially. With the plated-shaped particles (P2), the filter medium resistance is always below the particles P1 by a factor of $2-5$. One explanation is again the spatial structure, which at $\mathrm{P} 2$ obstruct the penetration of the particles into the tissue, and thus inhibits the interference resistance. With the needle-shaped particles (P3) this trend becomes even clearer. The needle-shaped structure prevents many particles from interacting with the fabric and thus ensures the lowest filter resistance in all measurements. So, the resistance is below particle system P1 by a factor of 5 up to 10 .

A result is that particle interaction has a significant effect on the filtration properties of filter fabrics. This influence becomes apparent with decreasing mesh size, and thus particle size and can lead to a strong reduction of the hydraulic load capacity or the overall performance of the filter apparatus.

Author Contributions: Conceptualization, P.M.; Data curation, V.B.; Formal analysis, V.B.; Funding acquisition, M.G. and H.N.; Investigation, V.B. and B.F.; Methodology, V.B., P.M. and B.F.; Project administration, P.M.; Resources, P.M.; Software, V.B., P.M. and B.F.; Supervision, P.M., M.G. and H.N.; Validation, V.B.; Visualization, V.B.; Writing—original draft, V.B. and P.M.; Writing—review \& editing, B.F., M.G. and H.N. All authors have read and agreed to the published version of the manuscript.

Funding: This research received no external funding.

Institutional Review Board Statement: Not applicable.

Informed Consent Statement: Not applicable.

Data Availability Statement: Not applicable.

Acknowledgments: The authors would like to thank the German Federation of Industrial Research Associations (AiF) for the financial support (IGF number $18591 \mathrm{~N}$ ). The authors would also like to thank all colleagues and students for the support in writing this paper. Furthermore, the authors express their thanks to GKD-Gebrüder Kufferrath AG (Germany), especially Markus Knefel and Dominik Herper for supplying the used metallic fabric samples. An additional gratitude applies to Chwolka and Hoffmann from Sefar AG (Switzerland) and Markus Süsser from Müller AG (Switzerland) for their supply with polymeric filter cloths. We acknowledge support by the KIT-Publication Fund of the Karlsruhe Institute of Technology. 
Conflicts of Interest: The authors declare no conflict of interest.

\section{Abbreviations}

$\begin{array}{lll}\text { Symbol } & \text { Description } & \text { Unit } \\ \mathrm{A} & \text { Filter surface } & \mathrm{m}^{2} \\ \mathrm{~d}_{\text {Mesh }} & \text { Mesh size of filter cloth based on a bubble-point-test } & \mathrm{m} \\ \mathrm{H}_{\mathrm{FC}} & \text { Filter cake height } & \mathrm{m} \\ \mathrm{K} & \text { Parameter Filter equation } & - \\ \mathrm{q} & \text { Parameter Filtration mechanism according to [14] } & - \\ \mathrm{R}_{\mathrm{FC}} & \text { Filter cake resistance } & \mathrm{m}^{-1} \\ \mathrm{R}_{\mathrm{F} \cdot 0} & \text { Initial resistance at the beginning of the Filtration } & \mathrm{m}^{-1} \\ \mathrm{R}_{\mathrm{FM}} & \text { Filter medium resistance } & \mathrm{m}^{-1} \\ \mathrm{R}_{\mathrm{FM}, 0} & \text { Clear water resistance of the filter fabric } & \mathrm{m}^{-1} \\ \mathrm{R}_{\mathrm{IR}} & \text { Interference resistance [19]; Interaction between filter fabric and particles } & \mathrm{m}^{-1} \\ \mathrm{R}_{\mathrm{Support}} & \text { Resistance of the supporting fabric; Tends to 0 compared to the filter fabric. } & \mathrm{m}^{-1} \\ \mathrm{~V}_{\mathrm{F}} & \text { Filtrate volume } & \mathrm{m}^{3} \\ \dot{V}_{\mathrm{F}} & \text { Filtrate volume flow } & \mathrm{m}^{3} \cdot \mathrm{s}^{-1} \\ x_{50,3} & \text { Mass/volume related modal value } & \mathrm{m} \\ \alpha_{\mathrm{H}} & \text { Specific filter cake resistance } & \mathrm{m}^{-2} \\ \Delta \mathrm{p} & \text { Pressure difference } & \mathrm{Pa}^{-2} \\ \eta_{\mathrm{f}} & \text { Viscosity } & \mathrm{Pa}^{-} \mathrm{s} \\ \chi=\mathrm{A} \cdot \mathrm{H}_{\mathrm{FC}} / \mathrm{V}_{\mathrm{F}} & \text { Specific cake volume/filtrate volume } & \mathrm{m}^{3} \cdot \mathrm{m}^{-3}\end{array}$

\section{References}

1. Rocha, S.M.S.; Bacelos, M.S.; Damasceno, J.J.R.; Vieira, L.; Aguiar, M.L. The Effect of the Dust Cake Resistance on Fluid Flow Passing through the Filter Media. MSF 2012, 727-728, 758-763. [CrossRef]

2. Jaganathan, S.; Tafreshi, H.V.; Pourdeyhimi, B. A realistic approach for modeling permeability of fibrous media: 3-D imaging coupled with CFD simulation. Chem. Eng. Sci. 2008, 63, 244-252. [CrossRef]

3. Wakeman, R. The influence of particle properties on filtration. Sep. Purif. Technol. 2007, 58, 234-241. [CrossRef]

4. Rushton, A.; Griffiths, P.V.R. Role of the cloth in filtration. Chem. Eng. 2004, 4, 47-54.

5. Rushton, A. Effect of Filter Cloth Structure on Flow Resistance, Bleeding, Blinding and Plant performance. Chem. Eng. 1970, 273, 88-94.

6. Zhang, Q.; Horst, D.; Schmidt, E. Modellierung der Oberflächenstruktur von Nadelfilz-Filtermedien zur Simulation der kuchenbildenden Staubfiltration. Chem. Ing. Tech. 2020, 92, 275-281. [CrossRef]

7. Zhang, Q.; Schmidt, E. Simulation der Partikelschichtablösung unter Beachtung transienter kinetischer Effekte. Chem. Ing. Tech. 2008, 80, 587-592. [CrossRef]

8. Ripperger, S.; Puga, J.F.; Tichy, J.W. Einfluss des Filtermittelwiderstandes und der Strömungswiderstände im Filtratablaufb bbei kontinuierlich betriebenen Filtern mit hohem Feststoffdurchsatz. Filtr. Sep. 2005, 19, 58-62.

9. Purchas, D.B.; Sutherland, K. Handbook of Filter Media; Elsevier Advanced Technology: Oxford, UK, 2002.

10. Darcy, H. Les Fontaines Publiques de la Ville de Dijon: Exposition et Application des Principes à Suivre et des Formules à Employer dans les Questions de Distribution d'eau; Victor Dalmont: Paris, France, 1856.

11. Ergun, S. Fluid flow through packed columns. Chem. Eng. Prog. 1952, 48, 89-94.

12. Kozeny, J. Über kapillare Leitung des Wassers im Boden. Sitz. Akad. Wiss. Wien. 1927, 136, 271-306.

13. Carman, P.C. Fluid flow through granular beds. Trans. Inst. Chem. Eng. 1937, 15, 150-166. [CrossRef]

14. Hermans, P.H.; Bredée, H.L. Zur Kenntnis der Filtrationsgesetze. Recl. Travaux Chim. Pays-Bas. 1935, 54, 680-700. [CrossRef]

15. Erk, A. Rheologische Eigenschaften Feindisperser Suspensionen Während ihrer Fest-Flüssig-Trennung in Filtern und Zentrifugen; Shaker: Aachen, Germany, 2006.

16. Morsch, P.; Ginisty, P.; Anlauf, H.; Nirschl, H. Factors influencing backwashing operation in the liquid phase after cake filtration. Chem. Eng. Sci. 2020, 213, 115372. [CrossRef]

17. Heymann, J.; Böttner, P. Textile Filtermedien-Beschaffenheit und Eigenschaften. Filtr. Sep. 1997, 11, 43-51.

18. Tung, K.-L.; Li, Y.-L.; Lu', K.-T.; Lu, W.-M. Effect of calendering of filter cloth on transient characteristics of cake filtration. Sep. Purif. Technol. 2006, 48, 1-15. [CrossRef]

19. Tichy, J.W. Zum Einfluss des Filtermittels und der Auftretenden Interferenzen Zwischen Filterkuchen und Filtermittel bei der Kuchenfiltration. Ph.D. Thesis, Technische Universität Kaiserslautern, Kaiserslautern, Germany, 2007. Available online: https:/ / kluedo.ub.uni-kl.de/frontdoor/index/index/docId/1856 (accessed on 22 May 2007).

20. Anlauf, H. Filtermedien zur Kuchenfiltration-Schnittstelle Zwischen Suspension und Apparat. Chem. Ing. Tech. 2007, 79, 1821-1831. [CrossRef] 
21. Morsch, P.; Ginisty, P.; Anlauf, H.; Nirschl, H. Influence of regeneration variables during backwashing treatment into gas-phase after liquid filtration. Sep. Purif. Technol. 2020, 249, 11707. [CrossRef]

22. Morsch, P.; Kühn, J.; Werner, R.; Anlauf, H.; Geier, D.U.; Becker, T.; Nirschl, H. Influence of the filter cloth and nozzles type on the in-situ cleaning procedure of filter presses. Chem. Eng. Sci. 2020, 226, 115889. [CrossRef] 